\title{
Associations of television viewing time with excess body weight among urban and rural high-school students in regional mainland China
}

\author{
Fei $\mathrm{Xu}^{1,2, *}$, JieQuan $\mathrm{Li}^{1}$, Robert S Ware ${ }^{3}$ and Neville Owen ${ }^{4}$ \\ ${ }^{1}$ Nanjing Municipal Center for Disease Control and Prevention, 2 Zizhulin, Nanjing 210003, People's Republic \\ of China: ${ }^{2}$ Department of Epidemiology and Biostatistics, Nanjing Medical University School of Public Health, \\ Nanjing, People's Republic of China: ${ }^{3}$ School of Population Health, The University of Queensland, Brisbane, \\ Australia: ${ }^{4}$ Cancer Prevention Research Centre, The University of Queensland, Brisbane, Australia
}

Submitted 3 May 2007: Accepted 9 September 2007: First published online 16 November 2007

\begin{abstract}
Objective: To examine the relationship between television (TV) viewing and body mass index (BMI) among adolescents in a region of mainland China.

Design: Population-based cross-sectional study, conducted between September and November of 2004, on a sample of enrolled high-school students aged 12-18 years.

Setting: One hundred and sixty-eight classes randomly selected from both urban and rural areas and belonging to 15 senior and 41 junior high schools in Nanjing, China, with a regional population of 6.0 million.

Subjects: In total 6848 students participated; $47.7 \%$ from urban and $52 \cdot 3 \%$ from rural areas; $49.0 \%$ male and $51.0 \%$ female. The response rate among eligible participants was $89.3 \%$.

Results: The proportion of overweight was $6.6 \%$ according to the criteria of overweight recommended for Chinese adolescents. Boys than girls (8.9\% vs. $4.4 \%$ ) had higher odds of being overweight (odds ratio (OR) 2.12, $95 \%$ confidence interval (CI) $1.74,2 \cdot 60$ ), while the proportion of overweight was significantly lower among rural students than urban students (4.5\% vs. $8.9 \%$; OR $0 \cdot 49,95 \%$ CI $0 \cdot 40,0 \cdot 60$ ). Those students who watched TV for more than $7 \mathrm{~h} /$ week had a 1.5 times greater odds of being overweight relative to their counterparts who watched TV for $7 \mathrm{~h} /$ week or less (adjusted OR 1.51, $95 \%$ CI 1.24, 1.82). Furthermore, there was a positive linear relationship between TV viewing time and BMI, even after adjusting for age, gender, residence area, time spent in study, in sleeping and in physical activity, and monthly pocket money.

Conclusions: Viewing TV might increase the likelihood of being overweight for Chinese adolescents in China.
\end{abstract}

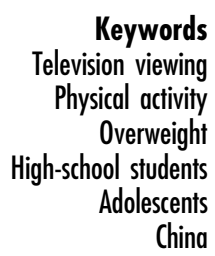

The increasing prevalence of excess body weight among children and adolescents is a global concern for public health $^{(1-5)}$. Being overweight or obese leads to adverse metabolic effects on blood pressure, cholesterol, triacylglycerols and insulin resistance ${ }^{(6-8)}$. Furthermore, excess body weight during adolescence predicts adult obesity, and childhood obesity influences morbidity and mortality in adult life ${ }^{(9-13)}$.

Time spent viewing television (TV) and videos is positively associated with obesity among adolescents in Western countries ${ }^{(14-20)}$. Several recent studies have reported the relationship between TV viewing and excess body weight to be independent of physical activity ${ }^{(21-25)}$. However, in previous studies, time sitting spent in classrooms and studying at home have not been taken into consideration.

In China, students spend much more time in sitting for study purposes, relative to their counterparts in Western countries $^{(26)}$. Thus, it is of unique importance to examine the associations of time spent viewing TV or videos with excess body weight among young people in China, after accounting for sitting time for study.

We conducted a large-scale, population-based survey of adolescents between September and November of 2004 in Nanjing, mainland China. We hypothesised that TV viewing would be positively associated with excess body weight, after controlling for time spent in sitting for study purposes, in leisure-time physical activity and in sleeping. 


\section{Participants and methods}

\section{Sample selection}

A large-scale, population-based, cross-sectional survey, the Nanjing High School Students' Health Survey, was conducted in Nanjing municipality, which is located in eastern China, with a total population of about 6.0 million in 2004. It has 13 administrative units; 11 urban districts and two rural counties since 2003. In mainland China, the schooling system consists of four strata: nursery school, primary school (grade 1-6), high school (junior: grade 7-9, senior: grade 10-12) and college/university. The class-based samples were selected using a multistage sampling method. First, we estimated the number of participants based on the lowest rate of risk behaviour reported in previous studies. The lowest rate was $4.5 \%$ for depression among adolescents; thus, the total number of participants required was estimated to be 6800. Second, according to the total number of grade-specific enrolled students and high schools by district/county in 2003, we calculated the sample size and sampling proportion for each administrative district or county. Third, based on the estimation of approximately 50 students in one class and the sample size, the number of participating classes was calculated for each administrative district or county. Fourth, taking the principle that one class would be randomly selected from each grade in each selected school, the number of participating schools was calculated; and then we randomly selected schools within each administrative district or county. Finally, each class was randomly selected from each grade within each chosen high school. This resulted in a total of 168 classes from 15 senior high schools and 41 junior high schools. All students from these selected classes were included in this study. The study was approved by the academic and ethical committee of Nanjing Municipal Center for Disease Control and Prevention, and conducted in accordance with the internationally agreed ethical principles for medical research involving human subjects (World Medical Association Declaration of Helsinki).

\section{Questionnaire and definitions}

After informed consent was obtained, the students were administered the face-to-face interview by trained healthcare professionals. The questionnaire sought general information, such as age, gender, grade, class, total weekly pocket money, body weight and height, status of parents' job and education, personal life events, and then asked specific questions related to time spent viewing TV (TV time), time sitting for course study (study time), time spent sleeping (sleeping time) and time engaged in physical activity (PA time).

Each student reported his/her time spent in viewing TV, sitting for course study, sleeping and doing physical activity according to the question: 'How much time (in minutes) did you ever spend in watching TV, sitting for course study, sleeping and doing physical activity at a typical weekday in past two weeks, respectively?' And the same question was also asked for the time at a typical weekend day. Then, TV time, study time, sleeping time and PA time were calculated respectively as the average weekly time in minutes based on the time spent on weekdays (five days) and weekend days (two days). To examine its association with body weight, TV time was treated as a continuous variable and was also categorised as $\leq 7 \mathrm{~h} /$ week and $>7 \mathrm{~h} /$ week. Study time, sleeping time and PA time were classified into tertiles, and were adjusted for in analyses via regression models. Also, total weekly pocket money reported by each student was divided into tertiles.

Body weight $(\mathrm{kg})$ and height $(\mathrm{cm})$ were self-reported by students. Body mass index (BMI) was calculated by dividing weight $(\mathrm{kg})$ by the square of height $\left(\mathrm{m}^{2}\right)$. Overweight was defined as $\mathrm{BMI} \geq 85$ th percentile value for age- and sex-specific reference data according to the recommendation for Chinese adolescents by the Group of China Obesity Task Force ${ }^{(27)}$. In China, all students are required to have their body weight and height measured in the commencement month (generally September) of each academic year. This was the most important reason why we conducted this study between September and November: to reduce potential recall error for selfreported body weight and height.

\section{Data management and analysis}

First, we calculated the prevalence of overweight in each population group. Then, we examined the relationship between BMI and time spent viewing TV, which were treated as continuous variables, using linear regression models. Next, we examined the associations between overweight and TV time categories using logistic regression analysis. In both linear and logistic regression analyses, three models were introduced: Model 1 with TV time as the single predictor; Model 2 with adjustment for age, gender and residence area; and Model 3 with adjustment for duration of other times (study time, sleeping time, PA time) and monthly pocket money, in addition to age, gender and residence area.

Data were double-entered and cleaned with EpiData version 3.0 (Epidata Association, Odense, Denmark), and managed and analysed using SPSS version 11.0.1, (SPSS Inc., Chicago, IL, USA). Data were weighted according to sample scheme coefficients.

\section{Results}

The total number of survey respondents was 6848; a response rate of $89.3 \%$. There were no significant demographic differences between respondents and those 
Table 1 Prevalence of overweight and its association with age, gender and urban-rural residence area among high-school students (total number of subjects $=6848$ ) in Nanjing, China

\begin{tabular}{lll}
\hline & \multicolumn{2}{c}{ Overweight* $^{\star}$} \\
\cline { 2 - 3 } & Prevalence, \% $(n / M)$ & OR $(95 \% \mathrm{Cl})$ \\
\hline Overall & $6.6(451 / 6848)$ & \\
Age (years) & & \\
$\leq 13$ & $9.2(140 / 1520)$ & 1.00 (referent) \\
14 & $6.4(105 / 1646)$ & $0.67(0.52,0.87)$ \\
15 & $5.6(94 / 1686)$ & $0.58(0.44,0.76)$ \\
16 & $7.2(49 / 685)$ & $0.76(0.54,1.07)$ \\
17 & $5.0(35 / 703)$ & $0.52(0.35,0.76)$ \\
$18+$ & $4.6(28 / 608)$ & $0.48(0.31,0.72)$ \\
Residence & & 1.00 (referent) \\
Urban & $8.9(289 / 3265)$ & $0.49(0.40,0.60)$ \\
$\quad$ Rural & $4.5(163 / 3583)$ & 1.00 (referent) \\
Gender & $4.4(153 / 3494)$ & $2.12(1.74,2.60)$ \\
$\quad$ Girls & $8.9(298 / 3354)$ & \\
Boys &
\end{tabular}

$n$, number of participants within subgroup; $N$, total number of participants within subgroup; OR, odds ratio; $\mathrm{Cl}$, confidence interval.

*Overweight was defined as body mass index $\geq 85$ th percentile value for age- and sex-specific reference data according to the recommendation for Chinese adolescents by the Group of China Obesity Task Force.

not taking part in this survey in terms of age, gender, grade and residence area. Table 1 shows the demographic characteristics of subjects and the proportion of them who were overweight. There were $47.7 \%$ of participants from urban areas and $52.3 \%$ from rural areas; $49.0 \%$ were boys and $51.0 \%$ were girls.

The overall prevalence of overweight in the sample population was $6.6 \%$. Boys more than girls $(8.9 \%$ vs. $4.4 \%)$ had a higher odds of being overweight (odds ratio (OR) $2 \cdot 12,95 \%$ confidence interval (CI) $1.74,2 \cdot 60$ ), while rural students had significantly lower odds of being overweight relative to their urban counterparts ( $4.5 \%$ vs. 8.9\%; OR 0.49, $95 \%$ CI 0.40, 0.60).

To explore the relationship between BMI and time spent viewing TV among the high-school students, we conducted a linear regression analysis using BMI and TV time as continuous variables (Table 2). Outcomes from the model showed that TV time could explain only a very small proportion $(0.1 \%)$ of the variation in the participants' BMI, and BMI was positively associated with time spent watching TV $(P=0.002)$. On average, an increase in time viewing TV of $1 \mathrm{~h} /$ week was associated with a 0.011 unit increase in BMI when potential confounders were taken into consideration (Model 1). The strength of the association of BMI with TV time was attenuated, but still significant, after controlling for age, gender and residence area (Model 2). The association between BMI and TV time remained significant in Model 3 after adjusting for age, gender, residence area, other time (study time, sleeping time, PA time) and monthly pocket money.

Table 3 presents the associations of BMI with TV time, by gender and area of residence. Using BMI as the outcome variable and TV time as the single exposure
Table 2 The association of BMI with TV time* among high-school students in Nanjing, China

\begin{tabular}{lccc}
\hline & $B$ & SE & $P$ value \\
\hline Model 1† & 0.011 & 0.004 & 0.002 \\
Model 2‡ & 0.007 & 0.003 & 0.027 \\
Model 3§ & 0.007 & 0.003 & 0.032
\end{tabular}

BMI, body mass index; TV time, time spent watching television; SE, standard error.

${ }^{*} \mathrm{BMI}$ and TV time were both considered as continuous variables.

tModel 1: odds ratio calculated via univariate linear regression model.

¥Model 2: odds ratios calculated via multivariate linear regression model with adjustment for age, gender and residence area.

$\S$ Model 3: odds ratios calculated via multivariate linear regression model with adjustment for age, gender, residence area, other time (study time, sleeping time, physical activity time), and monthly pocket money.

Table 3 The association of BMI with TV time* by gender and urban-rural area among high-school students in Nanjing, China

\begin{tabular}{llllll}
\hline & \multicolumn{2}{c}{ Gender } & & \multicolumn{2}{c}{ Residence area } \\
\cline { 2 - 3 } & Male & Female & & Urban & Rural \\
\hline Model 1+ & & & & \\
$B$ & 0.016 & 0.007 & & 0.002 & 0.015 \\
SE & 0.005 & 0.005 & & 0.006 & 0.005 \\
$P$ value & 0.001 & 0.176 & & 0.726 & 0.001 \\
\hline
\end{tabular}

BMI, body mass index; TV time, time spent watching television, SE, standard error.

${ }^{*} \mathrm{BMI}$ and TV time were both considered as continuous variables.

tModel 1: odds ratio calculated via univariate linear regression model.

variable, we found a positive relationship between BMI and TV time within each stratum of gender and residence area; however, this association was significant only among male and rural adolescents.

TV time was also examined as a categorical variable ( $\leq 7 \mathrm{~h} /$ week and $>7 \mathrm{~h} /$ week) to further explore its association with overweight. As shown in Table 4, those students who watched TV for more than $7 \mathrm{~h} /$ week had 1.5 times greater odds of being overweight, relative to their counterparts who watched TV for $7 \mathrm{~h} /$ week or less (adjusted OR 1.51, 95\% CI 1.24, 1.82) (Model 1). After holding constant age, gender, residence area, and/or other sedentary time and monthly pocket money, participants watching TV for more than $7 \mathrm{~h} /$ week still had a significantly higher odds of being overweight compared with their counterparts who watched TV for $7 \mathrm{~h} /$ week or less (Model 2 and 3).

\section{Discussion}

In a large sample of Chinese adolescents, we found that the prevalence of overweight (based on the reference by the Group of China Obesity Task Force) was $6.6 \%$, which is higher than that $(5.8 \%)$ calculated based on the category criterion of overweight recommended by the US National Center for Health Statistics ${ }^{(27,28)}$. This figure is lower than those reported in studies from developed 
Table 4 The association of overweight with TV time* among high-school students in Nanjing, China

\begin{tabular}{|c|c|c|c|c|}
\hline \multirow[b]{3}{*}{ TV time } & \multicolumn{4}{|c|}{ Overweightt } \\
\hline & \multirow[b]{2}{*}{ Prevalence, \% $(n / N)$} & \multirow{2}{*}{$\frac{\text { Model } 1 \ddagger}{\text { OR }(95 \% \mathrm{Cl})}$} & \multirow{2}{*}{$\frac{\text { Model } 2 \S}{\text { tted OR }(95 \% \mathrm{Cl})}$} & \multirow{2}{*}{$\frac{\text { Model } 3 \|}{\text { sted OR }(95 \% \mathrm{Cl})}$} \\
\hline & & & & \\
\hline$\leq 7 \mathrm{~h} /$ week & $5.4(201 / 3704)$ & 1.00 (referent) & 1.00 (referent) & 1.00 (referent) \\
\hline$>7 \mathrm{~h} /$ week & $8.0(250 / 3144)$ & $1.51(1.24,1.82)$ & $1.44(1.12,1.85)$ & $1.38(1.08,1.78)$ \\
\hline \multicolumn{5}{|c|}{$\begin{array}{l}\text { TV time, time spent watching television; } n \text {, number of participants within subgroup; } N \text {, total number of participants within subgroup; OR, odds ratio; Cl, } \\
\text { confidence interval. } \\
\text { *TV time was categorised as } \leq 7 \mathrm{~h} / \text { week and }>7 \mathrm{~h} / \text { week. } \\
\text { tOverweight was defined as body mass index } \geq 85 \text { th percentile value for age- and sex-specific reference data according to the recommendation for Chinese } \\
\text { adolescents by the Group of China Obesity Task Force. } \\
\text { łModel 1: OR calculated via univariate logistic regression model. } \\
\text { \$Model 2: OR calculated via multivariate logistic regression model with adjustment for age, gender and residence area. } \\
\text { IModel 3: OR calculated via multivariate logistic regression model with adjustment for age, gender, residence area, other time (study time, sleeping time, } \\
\text { physical activity time), and monthly pocket money. }\end{array}$} \\
\hline
\end{tabular}

countries $^{(2-4,29-31)}$, but similar to those documented in studies with the same overweight criterion in China ${ }^{(32,33)}$. If the increasing trend of overweight proportion continues among adolescents ${ }^{(4,5)}$, excess body weight in adolescents will be a major public health problem for China.

We focused our study specifically on the relationship between TV viewing time and overweight among Chinese high-school students. Our two major findings were that: (1) TV viewing time was positively associated with BMI among adolescents; and (2) compared with those who watched TV for $\leq 7 \mathrm{~h} /$ week, high-school students who watched TV for $>7 \mathrm{~h} /$ week had significantly higher odds of being overweight, which is consistent with several reports of studies carried out in Western countries ${ }^{(14-20)}$. We also considered two other major kinds of sedentary time, time spent in sitting for course study and in sleeping, in the same sample population. In our multivariate linear and the logistic regression models, study time and sleeping time as well as physical activity time were adjusted for; thus, our findings strengthen the case for a positive relationship between TV viewing time and the risk of overweight among adolescents.

In this study, the impact of TV viewing on overweight was positive, but very small. There was only a 0.011 unit increase in BMI when time spent viewing TV increased by $1 \mathrm{~h} /$ week. This is consistent with a recent and comprehensive meta-analysis study ${ }^{(34)}$. Thus, when interpreting the interesting findings, we must be prudent because the positive association was very weak.

It has been suggested that TV viewing may displace physical activity and thus be acting as a surrogate measure of reduced total energy expenditure ${ }^{(35)}$. For high-school students, their daily leisure time consists mainly of TV viewing time, study time, sleeping time, eating time and physical activity time, while most employed adults need not sit for such long regular study hours in their leisure time every day. Thus, adults have more discretionary leisure time, which permits them to spend time watching TV potentially without reducing their time for physical activity. However, typical Chinese students have to spend a large amount of compulsory study time at home on school evenings and on weekend days ${ }^{(26)}$; so, if they watch TV for longer periods, they are likely to have to reduce their time for physical activity and potentially for sleeping ${ }^{(36)}$. This would be our first explanation. However, a second explanation may be that TV viewing might also be associated with increased food and total energy intakes and poorer eating habits ${ }^{(25)}$, because individuals tend to eat while watching TV (and may thus be eating more energy-dense snack foods), together with their low physical activity levels ${ }^{(14,37)}$. Thus, when participants sit watching TV, they have a lower level of energy expenditure together with more energy intake.

Study time (involving at least the activities of reading and writing) would be expected to result in more energy expenditure compared with TV viewing ${ }^{(38)}$. TV viewing is a sedentary activity involving passive relaxation. Thus, the same time spent viewing TV and in sitting for study may have different impacts on energy expenditure. This may be another reason why TV viewing time may have a different impact on body weight from that of study time.

The positive relationship between TV time and BMI was significant among boys, but not among girls. Among participants of this study, boys spent significantly more time watching TV than girls (mean (standard deviation, SD), boys vs. girls: 7.6 (4.6) h vs. $7 \cdot 0$ (4.4) h; $P<0.001$ ). This was an explanation. In mainland China, there are very few gardens or parks, shops or stores, entertainment and exercise facilities in rural areas. Thus, compared with their urban counterparts, rural students may have fewer options for using their leisure time and thus may spend significantly more time watching TV (mean (SD), rural vs. urban: 7.5 (4.6) h vs. $7 \cdot 1(4.4) \mathrm{h} ; P=0.001)$. This might explain, at least partially, the finding that TV time was significantly positively associated with body weight among rural students, but not among those living in the urban areas. 
This is the first study to show positive, but weak, links between TV viewing time and body weight among highschool students in mainland China. It adds to the already strong evidence in the international literature on the relationship between TV viewing and overweight. We obtained a large-scale sample that was representative of the total population of high-school students in Nanjing, China. Times spent viewing TV, studying, sleeping and in physical activity were considered in the same sample population; thus, the influence of potential sources of confounding was able to be controlled. However, there were still three main limitations of our study. First, no causality can be inferred or implied, owing to the crosssectional nature of the study. Second, the self-report of body weight and height may result in possible error, even though we conducted the survey in the specially chosen month of September in order to reduce recall bias of body weight and height, as has previously been suggested for such epidemiological studies ${ }^{(39)}$. Third, all of our categories of sedentary and active time (TV viewing time, study time, sleeping time and physical activity time) were self-reported, and this may have resulted in some potential bias.

In conclusion, using data from a large representative population sample, our findings confirm those of previous studies that have shown significant, but weak, positive associations of TV viewing time with greater odds of overweight among adolescents; this relationship remained significant even after consideration of time spent in sitting for study purposes, sleeping and doing physical activity. These findings have significant implications for the roles of health officers and other professionals in mainland China: in developing policies and programmes to improve adolescent health in the shorter term and, importantly, to reduce the future burden of adult chronic diseases in the world's most populous country.

\section{Acknowledgements}

This study was funded by Nanjing Municipal Department of Health and Nanjing Municipal Department of Science and Technology. Our special thanks go to the schools and investigators for their support of the study.

The participation of Neville Owen was supported by a Queensland Health Core Infrastructure Grant room and by a Program Grant from the National Health and Medical Research Council of Australia (\#301200). Cathy Swart's assistance in preparation of this manuscript is also gratefully acknowledged.

No author declared conflicts of interest in this study. F.X. constructed the project design, quality control of data collection and writing of this paper; J.L. made his contribution by applying for funds and data collection; N.O. supervised the manuscript writing and manuscript editing; R.S.W. supervised statistics and language editing.

\section{References}

1. World Health Organization (1998) Obesity: Preventing and Managing the Global Epidemic. Report of a WHO Consultation on Obesity. Geneva: WHO.

2. Strauss RS \& Pollack HA (2001) Epidemic increase in childhood overweight 1986-1998. JAMA 286, 2845-2848.

3. Ogden CL, Flegal KM, Carroll MD \& Johnson CL (2002) Prevalence and trends in overweight among US children and adolescents, 1999-2000. JAMA 288, 1728-1732.

4. Wang YF, Monteiro C \& Popkin BM (2002) Trends of obesity and underweight in older children and adolescents in the United States, Brazil, China, and Russia. Am J Clin Nutr 75, 971-977.

5. Ji CY, Sun JL \& Chen TJ (2004) Dynamic analysis on the prevalence of obesity and overweight among school-age children and adolescents in recent 15 years in China. Chin J Epidemiol 25, 103-108.

6. Mokdad AH, Ford ES, Bowman BA, Dietz WH, Vinicor F, Bales VS \& Marks JS (2003) Prevalence of obesity, diabetes, and obesity-related health risk factors, 2001. JAMA 289, 76-79.

7. Cooperative Meta-analysis Group of China Obesity Task Force (2002) Predictive values of body mass index and waist circumference to risk factors of related diseases in Chinese adult population. Chin J Epidemiol 23, 5-8.

8. World Health Organization (2002) Reducing Risks, Promoting Healthy Life. World Health Report 2002. Geneva: WHO.

9. Guo SS, Roche AF, Chumlea WC, Gardner JD \& Siervogel RM (1994) The predictive value of childhood body mass index values for overweight at age 35 y. Am J Clin Nutr 59, 810-819.

10. Serdula MK, Ivery D, Coates RJ, Freedman DS, Williamson DF \& Byers T (1993) Do obese children become obese adults? A review of the literature. Prev Med 22, 167-177.

11. Power C, Lake JK \& Cole TJ (1997) Measurement and longterm health risks of child and adolescent fatness. Int J Obes Relat Metab Disord 21, 507-526.

12. Bray GA, Bouchard C \& James WPT (1998) Handbook of Obesity. New York: Marcel Dekker.

13. Must A \& Strauss RS (1999) Risks and consequences of childhood and adolescent obesity. Int J Obes Relat Metab Disord 23, Suppl. 2, S2-S11.

14. Dietz WH \& Gortmaker SL (1985) Do we fatten our children at the television set? Obesity and television viewing in children and adolescents. Pediatrics $\mathbf{7 5}$, 807-812.

15. Andersen RE, Crespo CJ, Bartlett SJ, Cheskin LJ \& Pratt M (1998) Relationship of physical activity and television watching with body weight and level of fatness among children: results from the Third National Health and Nutrition Examination Survey. JAMA 279, 938-942.

16. Gortmaker SL, Dietz WH \& Cheung LW (1990) Inactivity, diet and the fattening of America. J Am Diet Assoc 90, $1247-1255$.

17. Guillaume M, Lapidus L, Bjorntorp P \& Lambert A (1997) Physical activity, obesity, and cardiovascular risk factors in children. The Belgian Luxembourg Child Study II. Obes Res $\mathbf{5}, 549-556$

18. Gortmaker SL, Must A, Sobol AM, Peterson K, Colditz GA \& Dietz WH (1996) Television viewing as a cause of increasing obesity among children in the United States, 1986-1990. Arch Pediatr Adolesc Med 150, 356-362.

19. Obarzanek E, Schreiber GB, Crawford PB, Goldman SR, Barrier PM, Frederick MM \& Lakatos E (1994) Energy intake and physical activity in relation to indexes of body fat: the National Heart, Lung, and Blood Institute Growth and Health Study. Am J Clin Nutr 60, 15-22.

20. Locard E, Mamelle N, Billette A, Miginiac M, Munoz F \& Rey S (1992) Risk factors of obesity in a five-year-old 
population. Parental versus environmental factors. Int $J$ Obes 16, 721-729.

21. Hanley AJG, Harris SB, Gittelsohn J, Wolever TMS, Saksvig B \& Zinman B (2000) Overweight among children and adolescents in a Native Canadian community: prevalence and associated factors. Am J Clin Nutr 71, 693-700.

22. Hernandez B, Gortmaker SL, Colditz GA, Peterson KE, Laird NM \& Para-Cabrera S (1999) Association of obesity with physical activity, television programs and other forms of video viewing among children in Mexico City. Int J Obes Relat Metab Disord 23, 845-854.

23. Salmon J, Bauman A, Crawford D, Timperio A \& Owen N (2000) The association between television viewing and overweight among Australian adults participating in varying levels of leisure-time physical activity. Int J Obes Relat Metab Disord 24, 600-606.

24. Hu FB, Li TY, Colditz GA, Willett WC \& Manson JE (2003) Television watching and other sedentary behaviors in relation to risk of obesity and type 2 diabetes mellitus in women. JAMA 289, 1785-1791.

25. Dunstan DW, Salmon J, Owen N, Armstrong T, Zimmet PZ, Welborn TA, Cameron AJ, Dwyer T, Jolley D \& Shaw JE (2005) Associations of TV viewing and physical activity with the metabolic syndrome in Australian adults. Diabetologia 48, 2254-2261.

26. Yang XZ \& Liu BC (2002) Cross-sectional comparison of study burden among students in different countries. Shanghai Educ Res 4, 58-61.

27. Group of China Obesity Task Force (2004) Body mass index for reference norm fro screening overweight and obesity in Chinese children and adolescents. Chin J Epidemiol 25, 97-102.

28. US Department of Health and Human Services, National Center for Health Statistics (1998) Third National Health and Nutrition Examination Survey, 1988-1994, NHANES III Second Laboratory Data File. CD-ROM Series 11, no. 2A. Hyattsville, MD: Centers for Disease Control and Prevention.

29. Wang Y (2001) Cross-national comparison of childhood obesity: the epidemic and the relationship between obesity and socioeconomic status. Int J Epidemiol 30, 1136-1137.
30. Patrick K, Norman GJ, Calfas KJ, Sallis JF, Zabinski MF, Rupp J \& Cella J (2004) Diet, physical activity, and sedentary behaviors as risk factors for overweight in adolescence. Arch Pediatr Adolesc Med 158, 385-390.

31. Lewis RD, Meyer MC, Lehman SC, Trowbridge FL, Bason JJ, Yurman KH \& Yin Z (2006) Prevalence and degree of childhood and adolescent overweight in rural, urban, and suburban Georgia. J Sch Health 76, 126-132.

32. Ma GS, Li YP, Hu XQ, Cui ZH, Yang XG \& Chen CM (2006) Report on childhood obesity in China (2). Verification of BMI classification reference for overweight and obesity in Chinese children and adolescents. Biomed Environ Sci 19, $1-7$.

33. Wang Y \& Wang JQ (2002) A comparison of international references for the assessment of child and adolescent overweight and obesity in different populations. Eur J Clin Nutr 56, 973-982.

34. Marshall SJ, Biddle SJH, Gorely T, Cameron N \& Murdey I (2004) Relationships between media use, body fatness and physical activity in children and youth: a meta-analysis. Int J Obes Relat Metab Disord 28, 1238-1246.

35. Magarey AM, Daniels LA \& Boulton TJ (2001) Prevalence of overweight and obesity in Australian children and adolescents: reassessment of 1985 and 1995 data against new standard international definitions. Med J Aust 174, 561-564.

36. Xiao L (2003) Analysis on leisure time among 1144 school students at compulsory education level in Nanjing. Chin J Sch Health 24, 288-289.

37. Jeffery RW \& French SA (1998) Epidemic obesity in the United States: are fast foods and television viewing contributing? Am J Public Health 88, 277-280.

38. Hu FB, Leitzmann MF, Stampfer MU, Colditz GA, Willett WC \& Rimm EB (2001) Physical activity and television watching in relation to risk of type 2 diabetes mellitus in men. Arch Intern Med 161, 1542-1548.

39. Willett W. Anthropometric measures and body composition. In Nutritional Epidemiology, 2nd ed., pp. 245-247 [W Willett, editor]. New York: Oxford University Press. 